\title{
A Fragilidade do Ensino da Meiose
}

\section{Frailty in the Teaching of Meiosis}

Sônia Aparecida Santiago'

Hernandes Faustino de Carvalho'

Universidade Estadual de Campinas (Unicamp), Instituto de Biologia, Campinas, SP, Brasil.
Autor correspondente: hern@unicamp.br

Resumo: Além de exigir enorme abstração, o ensino da Biologia Celular envolve temas complexos como a meiose. As implicações para o aprendizado são imensas, pois vários conteúdos de outras disciplinas, assim como aplicações tecnológicas, dependem desse conhecimento. Utilizamos dois instrumentos de avaliação para mapear o aprendizado da meiose em quatro cursos de graduação. O primeiro foi idealizado para medir o nível de conhecimento que os alunos trazem do Ensino Médio e o segundo, para avaliar o aprofundamento do aprendizado que acontece com a aula de meiose nos quatro cursos. Os dois instrumentos de avaliação revelam diferenças marcantes entre os diferentes cursos e apontam dificuldades associadas ao aprendizado da meiose, convergindo a aspectos relevantes que podem auxiliar na exploração dos conteúdos em aulas, como a quantificação da variabilidade gênica, não compreendida pela grande maioria dos alunos.

Palavras-chave: Meiose; Ensino-aprendizagem; Fragilidade no ensino; Ensino superior; Instrumentos de avaliação.

Abstract: In addition to requiring enormous abstraction, the teaching of Cell Biology involves complex topics such as meiosis. In this particular case, the implications of learning are enormous because various contents in other disciplines, as well as technological applications, depend on this knowledge. We used two assessment instruments (AI) to map the learning of meiosis in four undergraduate programs. The first was designed to measure the level of knowledge that students bring from high school, the second to assess the depth of learning that happens in the meiosis lesson in the four programs. Both Al reveal marked differences across the different programs and point out difficulties associated with the learning of meiosis, which converge to relevant aspects that can assist in the exploration of the contents in lessons, such as the quantification of gene variability, which is not understood by the vast majority of students. tools.

Keywords: Meiosis; Teaching-learning; Frailty in teaching Higher education; Evaluation

Recebido em: 17/02/2019

Aprovado em: 07/09/2019 


\section{Introdução}

O ensino dos conceitos de meiose nos diversos níveis de ensino tem sido objeto de observação por parte de docentes e pesquisadores, por gerar uma suposta defasagem na consolidação dos ensinamentos, assim proporcionando prejuízo nos assuntos subsequentes.

A meiose é um conteúdo da Biologia Celular com importância não apenas nos conceitos de reprodução, mas também no entendimento de processos como variabilidade genética e evolução. Segundo Alberts et al. (2017), a meiose é o processo básico de formação dos gametas, no qual o número de cromossomos é reduzido pela metade, possibilitando a reprodução da espécie. Para isso, a célula passa por duas divisões celulares (meiose I e meiose II). A meiose I segrega os cromossomos homólogos, compostos por um par de cromátides-irmãs unidas, enquanto na meiose II, semelhante à mitose convencional, ocorrerá a segregação das cromátides-irmãs de cada homólogo. Esses dois momentos de divisão celular possibilitam a formação dos gametas com metade do número de cromossomos (haploides), garantindo a reprodução sexuada.

Resumidamente, os fenômenos da meiose parecem simples, mas o que se observa são evidencias de uma deficiência na aprendizagem do assunto. Klautau-Guimarães et al. (2009) descrevem que os discentes alcançam os cursos de graduação com um déficit considerável de conhecimento sobre os assuntos precedentes aos ensinos de Genética. Dentre esses assuntos está a meiose, destacando-se que os alunos não adquirem competências sobre os conteúdos nos níveis básicos. Complementando esse pensamento, Borges, Silva e Reis (2017) destacam que os equívocos na consolidação do ensino básico sobre genética afetam a construção do conhecimento dos alunos, dificultando a compreensão do assunto em seus níveis de maior complexidade.

Borges, Silva e Reis (2017) relatam ainda que, apesar dos assuntos relacionados à genética despertarem a curiosidade dos alunos, eles não alcançam um nível aceitável de compreensão por diversas razões. Dentre elas estão o vocabulário específico da área, muitos termos técnicos e os cálculos matemáticos exigidos, dentre outros. Ainda sobre a dificuldade dos alunos nos níveis básicos, Moura et al. (2013) diz que a complexidade do assunto o torna de difícil aceitação por parte deles e justifica que parte da não aceitação dos conteúdos está na forma com que ele é exposto em sala de aula, nos recursos usados como ferramentas de ensino e na falta de conhecimento prévio dos discentes. Outro fator de relevância destacado pelas autoras refere-se às tecnologias e inovações utilizadas em sala de aula nos dias atuais. No entanto, a falta de contextualização delas impede uma absorção efetiva do conhecimento.

O discurso de Lima, Pinton e Chaves (2007), corrobora o de Moura et al. (2013), afirmando ainda que as distorções dos conhecimentos de biologia são preservadas pelos discentes até mesmo no Ensino Superior.

Uma justificativa para tal déficit, na visão de Lorbieski, Rodrigues e D'Arce (2010), está na falta de interconexão entre os assuntos da genética e sua relação com o cotidiano. Os autores relatam que os alunos não são capazes de relacionar divisão celular e diversidade genética com o cotidiano diário. Com relação a essa teoria, Salim et al. (2007) apoiam a falta de interconexão entre os conteúdos de genética e divisão celular com o cotidiano, deixando um vácuo no conhecimento e possibilitando que os alunos alcancem o ensino superior sem conhecimento apropriado, impedindo um avanço cognitivo desse saber. 
Para Goldbach, El-Hani e Martins (2009), os alunos têm dificuldades em identificar o que são alelos, genes, cromatina e cromossomos, e em associa-los à molécula de DNA. Ao serem apresentados a assuntos decorrentes, não alcançam o entendimento dos conceitos mais complexos.

Para Krasilchik (2000), Silva e Cicillini (2008), além das interconexões entre os assuntos da genética, o ensino da Biologia deve proporcionar ao discente o desenvolvimento de habilidades e competências para compreensão, sistematização e reelaboração dos fatos, possibilitando a aplicação dos assuntos. Para tal, Carabetta (2010) sugere que o incentivo investigativo do aluno deve ser explorado pelos procedimentos didáticos/pedagógicos, possibilitando a reflexão e a resolução de situações-problemas, que possam refletir a realidade dos discentes.

Outro ponto relevante no ensino da meiose é a fragmentação dos conteúdos em diferentes disciplinas. As Leis de Mendel, por exemplo, são ministradas separadas da meiose, impossibilitando que os alunos relacionem bem os fenômenos da meiose com variabilidade e herança gênica. Outro fator de muita dificuldade se refere à duplicação do DNA e à própria variação estrutural dos cromossomos. O desmembramento dos conceitos, neste caso, tem impacto negativo na construção do conhecimento por impedir que o aluno associe os diferentes conhecimentos.

Um fator que também merece atenção é a percepção do aluno em relação ao seu conhecimento (ou a falta dele), com possível impacto no desenvolvimento das competências específicas.

A complexidade inerente a assuntos como a meiose constitui fator dificultador da consolidação do aprendizado. Os diversos aspectos que podem envolver essa problemática, incentiva a busca por estratégias pedagógicas. No entanto, os esforços nesse sentido se concentram em grande parte para suprir os déficits trazidos do Ensino Médio.

Este artigo buscou mapear as lacunas na consolidação do ensino em alunos que chegam ao Ensino Superior e demonstrar como esses alunos consolidam os ensinamentos após as aulas na graduação. Há defasagem na compreensão do assunto em seu âmbito mais complexo apresentado na graduação? A metodologia de ensino pode realmente ser um fator na incompreensão do assunto?

\section{Metodologia}

Para identificar como os conteúdos sobre meiose são assimilados pelos alunos do Ensino Superior, utilizamos Instrumentos Avaliativos (IA), que buscaram classificar de forma qualitativa e/ou quantitativa as respostas obtidas antes e depois das aulas de meiose na graduação. Buscamos verificar o repertório sobre o assunto do discente ao ingressar na universidade e como consolidou esse ensinamento depois das aulas na graduação. Essa pesquisa avaliou alunos de quatro cursos de Ensino Superior, expostos a metodologias de ensinos diferentes de uma Instituição Pública e uma Privada.

O Instrumento Avaliativo inicial teve como objetivo analisar o nível de conhecimento que esses alunos têm quando ingressam no Ensino Superior. Para alcançar esse objetivo, foram aplicados a alunos que ainda não haviam passado pelas aulas de meiose na graduação. Já o segundo Instrumento Avaliativo foi aplicado a alunos que já haviam passado pelas aulas de meiose na graduação e buscou identificar os conhecimentos específicos do assunto com maior nível de complexidade. 
As questões seguiram dois formatos, usando a estratégia de perguntas abertas e fechadas, para mensurar o conhecimento do aluno e também a opinião dele em relação ao ensino e às formas de ensinar. O estudo foi aprovado pela Comissão de Ética em Experimentação com Humanos por meio do Parecer n. 1.842.871.

No primeiro Instrumento Avaliativo, o formulário foi impresso com as perguntas ordenadas de maneira a investigar o conhecimento prévio do aluno, intercalando momentos de reflexão, como na segunda pergunta, que solicita ao aluno avaliar o conhecimento dele sobre o assunto. A aplicação foi efetuada presencialmente com a colaboração dos docentes responsáveis. A intenção desse primeiro Instrumento Avaliativo foi adquirir dados do conhecimento sobre o assunto que os alunos têm ao ingressarem no Ensino Superior, assim analisando a questão da fragilidade da aprendizagem do tema.

A segunda parte da pesquisa foi efetuada por meio de formulário eletrônico, utilizando a plataforma Google Forms. Os questionários foram enviados para o endereço eletrônico dos alunos dos $3 .^{\circ}, 4 .^{\circ}$ e $5 .^{\circ}$ semestres, de acordo com o curso. Nessa segunda etapa, buscou-se identificar se os alunos consolidaram conceitos importantes da meiose, após as aulas nas duas Instituições de Ensino Superior (IES). Esse segundo Instrumento Avaliativo continha questões específicas que avaliaram três tópicos principais: (a) recombinação e variabilidade genética, (b) fases e fenômenos da meiose e (c) resultado final da meiose. Nesse instrumento de avaliação, além da especificidade da área, procuramos avaliar mais três pontos, (d) a visão do aluno sobre as razões para um desempenho desfavorável; (e) quais disciplinas relacionadas sofreriam impactos; e, por fim, (f) a aceitação de estratégias de ensino como ferramentas de ensino-aprendizagem.

Na primeira parte da pesquisa, contou-se com a colaboração de 224 alunos (quadro 1), sendo 85 alunos de uma IES privada e 139 de uma Instituição de Ensino Superior pública. Já na segunda parte, a colaboração foi de 103 alunos, entre $3 .^{\circ}, 4 .^{\circ}$ e $5 .^{\circ}$ semestre, sendo 48 da Instituição de Ensino Superior privada e 55 da Instituição de Ensino Superior pública.

Quadro 1 - Cursos, períodos, quantidade de participantes

\begin{tabular}{|c|c|c|c|}
\hline \multirow{4}{*}{$\mathbf{1}^{\circ}$ Instrumento Avaliativo } & Curso & Semestre & Número de alunos \\
\cline { 2 - 4 } & $\mathrm{A}$ & $1^{\circ}$ & 55 \\
\cline { 2 - 4 } & $\mathrm{B}$ & $1^{\circ}$ & 48 \\
\cline { 2 - 4 } & $\mathrm{C}$ & $1^{\circ}$ & 84 \\
\cline { 2 - 4 } & $\mathrm{D}$ & $2^{\circ}$ & 37 \\
\hline \multirow{3}{*}{$\mathbf{2}^{\circ}$ Instrumento Avaliativo } & $\mathrm{A}$ & $4^{\circ} \mathrm{e} 5^{\circ}$ & 25 \\
\cline { 2 - 4 } & $\mathrm{B}$ & $3^{\circ}$ & 19 \\
\cline { 2 - 4 } & $\mathrm{C}$ & $3^{\circ}$ & 30 \\
\cline { 2 - 4 } & $\mathrm{D}$ & $4^{\circ}$ & 29 \\
\hline
\end{tabular}

Fonte: elaborado pelos autores.

No quadro 2 é possível verificar as perguntas feitas no primeiro Instrumento Avaliativo, e, no quadro 3, estão as questões específicas elaboradas para avaliar três momentos do conteúdo de meiose, aplicadas no segundo Instrumento Avaliativo, bem como a investigação sobre na opinião do aluno sobre o que leva ao não aprendizado e à aceitação por estratégias didáticas de ensino. 
Quadro 2 - Questões do primeiro Instrumento Avaliativo

\begin{tabular}{|c|c|c|}
\hline Questões & Alternativas & Resposta satisfatória \\
\hline $\begin{array}{l}\text { 1. Descreva resumidamente o que } \\
\text { é meiose }\end{array}$ & Discursiva & $\begin{array}{l}\text { Meiose é o processo reducional que ocorre em gametas } \\
\text { para transformar células diploides em haploides. Para a } \\
\text { reprodução sex } 2 \text {. uada, é um processo de fundamental } \\
\text { importância, pois, na fecundação, tendo como exemplo } \\
\text { o ser humano, ter-se-á } 23 \text { cromossomos paternos e } 23 \\
\text { maternos, formando } 46 \text { cromossomos característicos } \\
\text { da espécie. }\end{array}$ \\
\hline $\begin{array}{l}\text { 2. Como você avalia seu conheci- } \\
\text { mento sobre meiose? } \\
0---10\end{array}$ & Escala & \\
\hline $\begin{array}{l}\text { 3. Quando você adquiriu os conhe- } \\
\text { cimentos sobre meiose? }\end{array}$ & $\begin{array}{l}\text { ( ) Ensino Médio e/ou no } \\
\text { ( ) Curso preparatório para } \\
\text { vestibular. }\end{array}$ & \\
\hline $\begin{array}{l}\text { 4. O que a meiose tem a ver com a } \\
\text { primeira Lei de Mendel? }\end{array}$ & Discursiva & $\begin{array}{l}\text { Na meiose, ocorre a segregação dos genes, durante a } \\
\text { formação dos gametas, sendo assim, pai e mãe passam } \\
\text { genes para os descendentes. Essa separação igual se } \\
\text { tornou conhecida como a primeira Lei de Mendel, ou } \\
\text { lei da segregação dos fatores. }\end{array}$ \\
\hline
\end{tabular}

Fonte: elaborado pelos autores.

\section{Quadro 3 - Questões do segundo Instrumento Avaliativo}

\begin{tabular}{|c|c|c|}
\hline Questões & Alternativas & Resposta satisfatória \\
\hline $\begin{array}{l}\text { 1. Em que fase da meiose ocorre o } \\
\text { pareamento dos cromossomos } \\
\text { homólogos e para que esse pare- } \\
\text { amento é importante? }\end{array}$ & $\begin{array}{l}\text { (a) Zigóteno: garante a possibilidade de } \\
\text { variabilidade genética. } \\
\text { (b) Paquíteno: garante a formação de cé- } \\
\text { lulas-filhas geneticamente idênticas à cé- } \\
\text { lula-mãe. } \\
\text { (c) Diplóteno: garante a variabilidade dos } \\
\text { gametas. } \\
\text { (d) Diacinese: garante a separação dos cro- } \\
\text { mossomos não homólogos. } \\
\text { (e) Leptóteno.: garante a duplicação do } \\
\text { DNA, indispensável a esse processo }\end{array}$ & (a) \\
\hline $\begin{array}{l}\text { 2. A formação de tétrades no parea- } \\
\text { mento cromossômico possibilita } \\
\text { um fenômeno denominado? }\end{array}$ & $\begin{array}{l}\text { (a) Quiasma. } \\
\text { (b) Cromômero. } \\
\text { (c) Sinapse. } \\
\text { (d) Crossing Over. } \\
\text { (e) Cromátides. }\end{array}$ & (d) \\
\hline $\begin{array}{l}\text { 3. Além da permuta, a segregação } \\
\text { aleatória de cada cromossomo } \\
\text { homólogo contribui para o au- } \\
\text { mento da variabilidade genética } \\
\text { dos gametas formados. Qual seria } \\
\text { a variabilidade introduzida pela } \\
\text { segregação aleatória dos cromos- } \\
\text { somos humanos (número diploide } \\
\text { de cromossomos }=46 \text { )? }\end{array}$ & Resposta discursiva & $\begin{array}{l}\text { A segregação independente poderá } \\
\text { produzir quatro tipos diferentes de } \\
\text { gametas. Portanto, o número de com- } \\
\text { binações possíveis pode ser expresso } \\
\text { por } 2 \mathrm{n} \text {, sendo n o número de pares } \\
\text { de cromossomos da espécie. Para a } \\
\text { espécie humana, por exemplo, que } \\
\text { possui } 23 \text { pares de cromossomos, a } \\
\text { possibilidade é de 223, ou seja, } 8,4 \\
\text { x } 106 \text { tipo de gametas (CARVALHO; } \\
\text { RECCO-PIMENTAL, 2013). }\end{array}$ \\
\hline $\begin{array}{l}\text { 4. Durante a fase de diplóteno, é } \\
\text { possível observar determinados } \\
\text { pontos onde as cromátides estão } \\
\text { cruzadas. Esses pontos são chama- } \\
\text { dos de: }\end{array}$ & $\begin{array}{l}\text { (a) Quiasmas. } \\
\text { (b) Bivalentes. } \\
\text { (c) Cromômeros. } \\
\text { (d) Tétrades. } \\
\text { (e) Sinapse cromossômica. }\end{array}$ & (a) \\
\hline $\begin{array}{l}\text { 5. Qual o conteúdo de DNA de um } \\
\text { óvulo? }\end{array}$ & Resposta discursiva & 23 cromossomos. \\
\hline $\begin{array}{l}\text { 6. A formação do zigoto é composto } \\
\text { por células geneticamente iguais } \\
\text { ou diferentes? Comente sua res- } \\
\text { posta. }\end{array}$ & Resposta discursiva & $\begin{array}{l}\text { São diferentes, pois, quando ocorre a } \\
\text { fusão dos gametas, a primeira célula } \\
\text { formada é o zigoto, que terá metade } \\
\text { dos cromossomos de origem paterna } \\
\text { e outra metade dos cromossomos de } \\
\text { origem materna. }\end{array}$ \\
\hline
\end{tabular}




\begin{tabular}{|c|c|c|}
\hline Questões & Alternativas & Resposta satisfatória \\
\hline $\begin{array}{l}\text { 7. Que assuntos relacionados a em- } \\
\text { briologia, histologia, fisiologia, } \\
\text { genética e/ou biologia molecular } \\
\text { teriam sido favorecidos por mais } \\
\text { conhecimentos ou melhor com- } \\
\text { preensão da meiose? }\end{array}$ & Resposta discursiva & \\
\hline $\begin{array}{l}\text { 8. O que você acredita ter sido fator } \\
\text { limitante para sua compreensão } \\
\text { da meiose e da sua importância? }\end{array}$ & $\begin{array}{l}\text { (a) Livro didático de difícil leitura. } \\
\text { (b) Complexidade do assunto. } \\
\text { (c) Não afinidade com a metodologia de } \\
\text { ensino adotada. } \\
\text { (d) Habilidade do docente em fazê-lo com- } \\
\text { preender os conceitos. } \\
\text { (e) Habilidade do docente em fazê-lo com- } \\
\text { preender a importância do assunto. }\end{array}$ & \\
\hline $\begin{array}{l}\text { 9. Em sua opinião, aulas práticas de } \\
\text { meiose em laboratórios ajudam a } \\
\text { absorver o assunto? }\end{array}$ & $\begin{array}{l}\text { () Sim. } \\
\text { ( ) Não. }\end{array}$ & \\
\hline $\begin{array}{l}\text { 10.Em sua opinião, estratégias de } \\
\text { ensino, como simuladores onli- } \\
\text { ne, que, interagindo com você, } \\
\text { simulassem as fases da meiose, } \\
\text { ajudá-lo-iam a absorver melhor } \\
\text { o assunto? }\end{array}$ & $\begin{array}{l}\text { () Sim. } \\
\text { ( ) Não. }\end{array}$ & \\
\hline $\begin{array}{l}\text { 11.Para você, estratégias de ensino } \\
\text { manuais, como montagem de } \\
\text { instrumentos com fios e cordas, } \\
\text { simulando as fases da meiose, } \\
\text { ajudá-lo-iam melhor que a forma } \\
\text { online? }\end{array}$ & $\begin{array}{l}\text { () Sim. } \\
\text { () Não }\end{array}$ & \\
\hline $\begin{array}{l}\text { 12.Para você, uma revisão teórica do } \\
\text { assunto que não conseguiu absor- } \\
\text { ver, orientada por um professor, } \\
\text { seria melhor que as demais estra- } \\
\text { tégias citadas? }\end{array}$ & $\begin{array}{l}\text { () Sim. } \\
\text { () Não }\end{array}$ & \\
\hline
\end{tabular}

Fonte: elaborado pelos autores.

Com a aplicação destes Instrumentos Avaliativos, foi possível observar os níveis de aprendizagem antes e depois dos ensinamentos da meiose no Ensino Superior. A importância desse mapeamento está na possibilidade de interferências didático-pedagógicas correcionais, para possibilitar um saneamento pontual dessa defasagem de aprendizagem.

\section{Resultados}

Os resultados do primeiro Instrumento Avaliativo demonstraram o conhecimento do aluno que ingressa nos cursos de graduação.

Na primeira questão, procurou-se avaliar o conhecimento de forma direta sem uma aplicação específica, somente a qualidade de cada resposta, sendo os resultados apresentados no quadro 4. O curso $C$ obteve resultados mais satisfatórios em relação aos cursos A, B e D. O curso $D$, em comparação com os demais cursos analisados, obteve resultado totalmente insatisfatório. 
Quadro 4 - Percentuais das respostas à Questão 1 do Primeiro Instrumento Avaliativo

\begin{tabular}{|c|c|c|c|c|}
\hline Questão 1 & Curso A \% & Curso B \% & Curso C \% & Curso D \% \\
\hline $\begin{array}{l}\text { Meiose é a divisão celular que resulta na produção de } 4 \text { célu- } \\
\text { las-filhas com metade da quantidade de DNA da célula mãe/ } \\
\text { células haploides }\end{array}$ & 49,1 & 58,3 & 15,0 & 0 \\
\hline Divisão reducional & 21,8 & 0 & 75,0 & 0 \\
\hline Formação de células germinativas & 12,7 & 0 & 6,0 & 0 \\
\hline Processo de divisão capaz de gerar variabilidade genética & 3,6 & 0 & 0 & 0 \\
\hline Processo de divisão celular & 1,81 & 8,3 & 4,0 & 67,6 \\
\hline Reprodução celular & & 12,5 & 0 & 0 \\
\hline Confundiram meiose com mitose & 10,9 & 6,3 & 0 & 8,1 \\
\hline Não souberam/sem conhecimentos & 0 & 14,6 & 0 & 24,3 \\
\hline
\end{tabular}

Fonte: elaborado pelos autores.

A segunda questão avaliou a autopercepção do aluno quanto ao conhecimento dele sobre a meiose, mediante uma escala de valores que se iniciava em zero e finalizava em 10, onde zero o aluno constatava que não havia aprendido nada sobre o assunto e 10 havia compreendido plenamente o assunto. Na figura 1, é possível observar a reação dos alunos ao se autoavaliarem.

Figura 1 - Autopercepção de desempenho dos alunos dos quatro cursos (questão 2 do primeiro Instrumento Avaliativo)
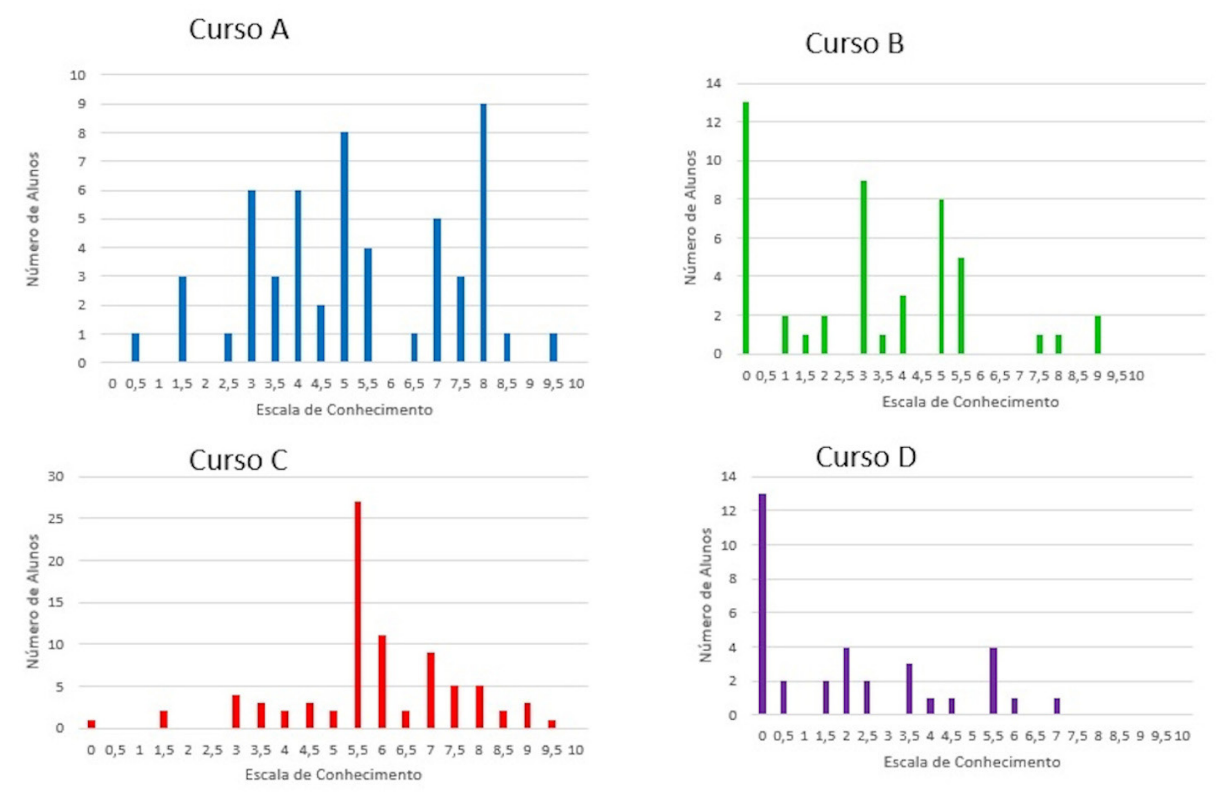

Fonte: elaborado pelos autores.

Nota-se um fato interessante com relação aos resultados desta questão: uma distribuição bimodal da autoavaliação dos alunos do curso A, com notas de 3 a 5,5 formando um grupo e as de 7 a 9,5, outro. Pelo menos, em termos da autopercepção dos seus conhecimentos, os alunos se dividem em dois grupos. 
Ao se autoavaliarem, 27\%, correspondendo a 13 alunos do curso B, atribuíram-se nota zero; cinco alunos ficaram na escala entre 1 e 2; oito deles, nota 3 e dois alunos com nota 3,5; cinco alunos se autoavaliaram com nota 4,0 e sete deles nota cinco. Oito alunos se autoatribuíram notas acima de 5 .

Quanto à autopercepção do conhecimento sobre a meiose, 13 alunos do curso D (um terço dos alunos) se autoatribuíram nota zero (figura 1).

Apesar de conseguirem responder as perguntas específicas sobre a meiose em sua grande maioria de forma satisfatória, os alunos do curso $C$ se autoavaliarem, atribuíram-se notas medianas (com média 5).

A abordagem da terceira questão amostrou a porcentagem de alunos que reforçaram seus ensinamentos com cursos preparatórios para vestibular, sendo os resultados apresentados no quadro 5.

Quadro 5 - Respostas à questão 3 do segundo Instrumento Avaliativo

\begin{tabular}{|l|r|r|r|r|}
\hline \multicolumn{1}{|c|}{ Questão 3 - Respostas } & Curso A \% & Curso B \% & Curso C \% & Curso D \% \\
\hline Somente no ensino médio & $\mathbf{7 0 , 9}$ & $\mathbf{7 9 , 2}$ & $\mathbf{3 5 , 7}$ & $\mathbf{8 3 , 8}$ \\
\hline Em cursos pré-vestibulares & 10,9 & 6,3 & $\mathbf{3 3 , 3}$ & 0 \\
\hline $\begin{array}{l}\text { Admitem ter aprendido no Ensino Médio e compreendido } \\
\text { melhor no curso pré-vestibular }\end{array}$ & 16,4 & 0 & $\mathbf{2 9 , 8}$ & 0 \\
\hline Afirma ter estudado sozinho & 1,8 & 0 & 0 & 0 \\
\hline Não se lembraram de ter aprendido sobre o assunto & 0 & 14,6 & 0 & 16,2 \\
\hline Não responderam & 0 & 0 & 1,2 & 0 \\
\hline
\end{tabular}

Fonte: elaborado pelos autores.

Na quarta questão, buscou-se avaliar o quanto o aluno consegue usar o conhecimento adquirido em aspectos multidisciplinares, isto é, relacionar os ensinamentos expostos em momentos diferentes. As respostas são apresentadas no quadro 6, onde é possível verificar que uma porcentagem alta de alunos não respondeu ou alegou não saber.

Quadro 6 - Respostas à questão 4, do segundo Instrumento Avaliativo

\begin{tabular}{|l|r|r|r|r|}
\hline \multicolumn{1}{|c|}{ Questão 4 - Respostas } & Curso A \% & Curso B \% & Curso C \% & Curso D \% \\
\hline $\begin{array}{l}\text { A primeira Lei de Mendel enuncia que as informações gênicas } \\
\text { são formadas por pares de características que separam na } \\
\text { formação de gametas". Isso pode ser com o pareamento de } \\
\text { homólogos e sua separação durante a meiose I. }\end{array}$ & 0 & 0 & 2,4 & 0 \\
\hline Crossing over & 0 & 0 & 1,2 & 0 \\
\hline Segregação independente & 36,4 & 0 & 57,1 & 0 \\
\hline Segregação em divisão celular & 5,5 & 25,0 & 2,4 & 0 \\
\hline Relacionaram com divisão celular & & & & 0 \\
\hline $\begin{array}{l}\text { Relacionaram a produção de novas características genéticas } \\
\text { ("combinação gênica") }\end{array}$ & 18,2 & 39,6 & 2,4 & 0 \\
\hline Relacionaram com variabilidade genética & & 0 & 13,1 & 0 \\
\hline Segregação de características genéticas & 0 & 0 & 32,4 \\
\hline União de gametas & 1,8 & 0 & 0 & 0 \\
\hline Herança de características & 9,1 & 0 & 11,9 & 0 \\
\hline Não responderam & $\mathbf{2 3 , 6}$ & $\mathbf{3 5 , 4}$ & 7,1 & 8,1 \\
\hline Não sabem & 5,5 & 0 & 0 & $\mathbf{5 9 , 5}$ \\
\hline Não se lembram de ter aprendido & 0 & 0 & 2,4 & 0 \\
\hline
\end{tabular}

Fonte: elaborado pelos autores. 
O primeiro Instrumento Avaliativo comprovou que os alunos do curso $C$ reproduzem os conceitos associados à meiose sem maiores dificuldades. No entanto, desperta uma análise a respeito da repetição de conteúdos que não necessariamente demonstra a construção do conhecimento. $\mathrm{O}$ que se busca na atualidade é deixar a repetição e aprimorar a reflexão.

Com as questões discursivas, pode-se avaliar a qualidade das respostas e, com exceção do curso C, os demais obtiveram níveis insatisfatórios, caracterizando um não aprendizado dos conceitos básicos de meiose e de genética.

Os resultados do segundo Instrumento Avaliativo se mostraram reveladores, pois, neste momento, avaliamos os discentes após as aulas de meiose na graduação, com um questionário que abordava três questões diretas e três que requisitavam deles um raciocínio voltado à aplicação dos conhecimentos adquiridos. Esse instrumento de avaliação também procurou mensurar outros aspectos, como se o aluno conseguiria avaliar o grau de importância do assunto meiose para outras disciplinas. Outro ponto analisado foi a opinião dos alunos referente ao motivo de um possível déficit de aprendizado neste assunto. Também se procurou investigar a aceitação dos alunos por estratégias de ensino como jogos.

Quadro 7 - Respostas satisfatórias às questões do segundo Instrumento Avaliativo

\begin{tabular}{|c|c|c|c|c|}
\hline Questão & Curso A \% & Curso B \% & Curso C \% & Curso D \% \\
\hline $\begin{array}{l}\text { 1. Em que fase da meiose ocorre o pareamento dos cromossomos } \\
\text { homólogos e para que esse pareamento é importante? }\end{array}$ & 28,0 & 68,4 & 83,3 & 48,0 \\
\hline $\begin{array}{l}\text { 2. A formação de tétrades no pareamento cromossômico possibilita } \\
\text { um fenômeno denominado? }\end{array}$ & 72,0 & 31,6 & 73,3 & 24,1 \\
\hline $\begin{array}{l}\text { 4. Durante a fase de diplóteno, é possível observar determinados } \\
\text { pontos onde as cromátides estão cruzadas. Esses pontos são } \\
\text { chamados de: }\end{array}$ & 88,0 & 79,0 & 60,0 & 31,0 \\
\hline $\begin{array}{l}\text { 8. O que você acredita ter sido fator limitante para a sua compreensão } \\
\text { da meiose e da sua importância? }\end{array}$ & & & & \\
\hline a) Livro didático de difícil leitura & 12,0 & - & 36,6 & - \\
\hline b) Complexidade do assunto & 16,0 & 52,6 & 40,0 & 65,5 \\
\hline c) Não afinidade com a metodologia de ensino adotada & 40,0 & 36,8 & 3,3 & 1 aluno \\
\hline d) Habilidade do docente em fazê-lo compreender os conceitos & 28,0 & 10,5 & 13,3 & 1 aluno \\
\hline $\begin{array}{l}\text { e) Habilidade do docente em fazê-lo compreender a importância } \\
\text { do assunto }\end{array}$ & 4,0 & - & 1 aluno & 27,9 \\
\hline $\begin{array}{l}\text { 9. Em sua opinião, as aulas práticas de meiose em laboratórios ajudam } \\
\text { a absorver o assunto? }\end{array}$ & 96,0 & 100,0 & 100,0 & 86,2 \\
\hline $\begin{array}{l}\text { 10.Em sua opinião, estratégias de ensino, como simuladores online, } \\
\text { que, interagindo com você, simulassem as fases da meiose, ajudá- } \\
\text {-lo-iam a absorver melhor o assunto? }\end{array}$ & 100 & 68,4 & 100,0 & 72,4 \\
\hline $\begin{array}{l}\text { 11.Para você estratégias de ensino manuais, como montagem de } \\
\text { instrumentos com fios e cordas, simulando as fases da meiose, } \\
\text { ajudá-lo-iam melhor que a forma online? }\end{array}$ & 80,0 & 84,2 & 53,3 & 65,5 \\
\hline $\begin{array}{l}\text { 12.Para você, uma revisão teórica do assunto que não conseguiu } \\
\text { absorver, orientada por um professor, seria melhor que as demais } \\
\text { estratégias citadas? }\end{array}$ & 16,0 & 36,8 & 76,7 & 37,9 \\
\hline
\end{tabular}

Fonte: elaborado pelos autores

A questão 3 tratava de um aspecto quantitativo e envolvia conhecimento básico de probabilidade. Um décimo dos alunos do curso B e 13\% dos alunos do curso C acertaram a resposta; nenhum aluno dos cursos $A$ e $D$ acertaram a resposta. Além disso, $80 \%$ do curso $A, 73 \%$ do curso $B, 23,3 \%$ do curso $C$ e $83 \%$ dos alunos do curso $D$ não responderam ou disseram não saber fazer esse cálculo. 
A questão 5 procurou identificar como o aluno articulava a divisão meiótica com a formação de gametas haploides. Mais da metade dos alunos (56\%) do curso A, 32\% do curso $B, 93 \%$ do curso $C$ e $31 \%$ do curso $D$ responderam que o óvulo tem 23 cromossomos ou são haploides. Muitos não associaram o conceito de conteúdo relativo de DNA, 32\% dos alunos do curso $A$ e $34 \%$ dos alunos do curso $D$ não responderam à questão, $22 \%$ dos alunos do curso B não souberam responder. Nenhum dos alunos do curso $C$ deixou de responder.

Com respeito à questão 6 , cerca de metade dos alunos dos diferentes cursos responderam que o zigoto se forma pela união de células geneticamente diferentes, mas a maioria não apresentou qualquer explicação ou comentário. O número de não respondentes variou ( $36 \%$ no curso $A, 26 \%$ no curso $B, 7 \%$ no curso $C$ e $21 \%$ no curso D). O que causa espanto é que $12 \%$ dos alunos do curso $A, 5,3 \%$ do curso $B, 6,7 \%$ do curso $C$ e $28 \%$ do curso $D$ afirmaram que as células que formam o zigoto são iguais.

Na figura 2, é possível avaliar os déficits de aprendizagem referente aos conteúdos específicos do assunto de forma consolidada.

Figura 2 - Mapeamento dos resultados específicos sobre meiose

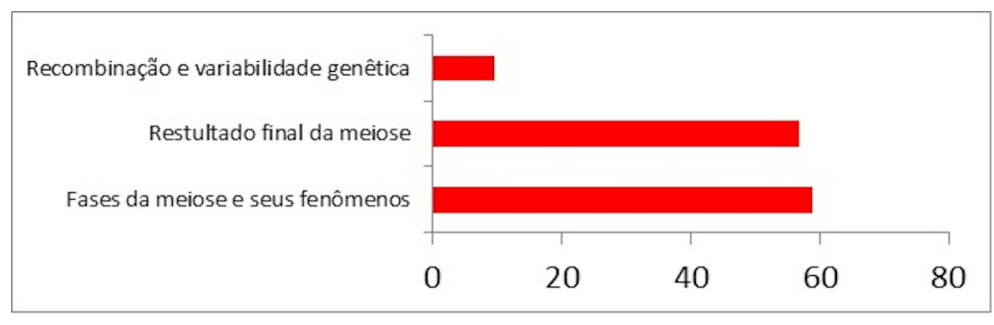

Fonte: elaborado pelos autores.

Ao serem questionados sobre assuntos prováveis que teriam se beneficiado de um melhor conhecimento da meiose, as respostas oscilaram entre escolher uma ou todas as áreas citadas na própria pergunta, $64 \%$ dos alunos do curso A, $53 \%$ do curso B, $23 \%$ do curso C e $28 \%$ do curso $D$ não responderam ou disseram não saber a resposta.

Para $96 \%$ dos alunos do curso A, o aprendizado se consolida com atividades práticas e todos eles acreditam que simuladores e estratégias digitais são válidas para o aprendizado. Ao serem questionados sobre ferramentas pedagógicas manuais, $80 \%$ se mostraram favoráveis a elas. Ao serem questionados sobre um reforço teórico como meio para suprir déficits de aprendizagem, 84\% discordaram dessa abordagem.

Na visão dos alunos de curso $B$, o déficit se relaciona com a complexidade do assunto tendo um percentual $52,6 \%$ nas respostas. Já $36,8 \%$ disseram não ter afinidade com o assunto e 10,52\% avaliaram que o problema é a habilidade do docente em fazê-los compreender os conceitos. Para $100 \%$ dos alunos deste curso, o aprendizado se consolida mediante práticas; $68,42 \%$ acreditam que simula dores e estratégias digitais são válidas para o aprendizado e, para $31,57 \%$, tais métodos não supririam seus déficits. Ao serem questionados sobre ferramentas pedagógicas manuais, $84,21 \%$ se mostraram favoráveis, enquanto $15,78 \%$ afirmaram não acreditar nessas estratégias. Ao serem questionados sobre um reforço teórico como meio para suprir déficits de aprendizagem, 63,15\% discordam dessa abordagem. 
$\mathrm{Na}$ opinião de $36,6 \%$ dos alunos do curso C, o livro didático é de difícil leitura; $40 \%$ acharam o assunto complexo; 3,3\% disseram não ter afinidade com o assunto; $13,3 \%$ relataram a habilidade do docente em fazê-lo compreender os conceitos da meiose; um deles disse ser a habilidade do docente em fazê-lo compreender a importância do assunto. Apenas um aluno não respondeu à questão.

Para $100 \%$ dos alunos do curso C, o aprendizado se consolida com as práticas e todos eles acreditam que simuladores e estratégias digitais são válidas para o aprendizado. Ao serem questionados sobre ferramentas pedagógicas manuais, 53,3\% se mostraram favoráveis, enquanto $46,6 \%$ mencionaram não acreditar nesse tipo de estratégia; três quartos deles (76,7\%) discordaram de que reforço teórico seria um bom meio para suprir as defasagens de aprendizagem.

Para a questão 'O que você acredita ter sido fator limitante para a sua compreensão da meiose e da sua importância?', a resposta com maior representatividade foi 'a complexidade do assunto', com 65,5\% dos alunos do curso D. Apenas um dos alunos relatou não ter afinidade com a metodologia de ensino adotada; outro associou suas dificuldades com a habilidade do docente em fazê-lo compreender os conceitos. Cerca de um terço dos alunos $(27,9 \%)$ associou suas dificuldades com a habilidade do docente em fazê-lo compreender a importância do assunto.

Na figura 3, estão representados de forma consolidada os resultados do déficit de aprendizagem na visão dos alunos.

Figura 3 - Consolidado: razões do déficit de aprendizagem na visão do aluno

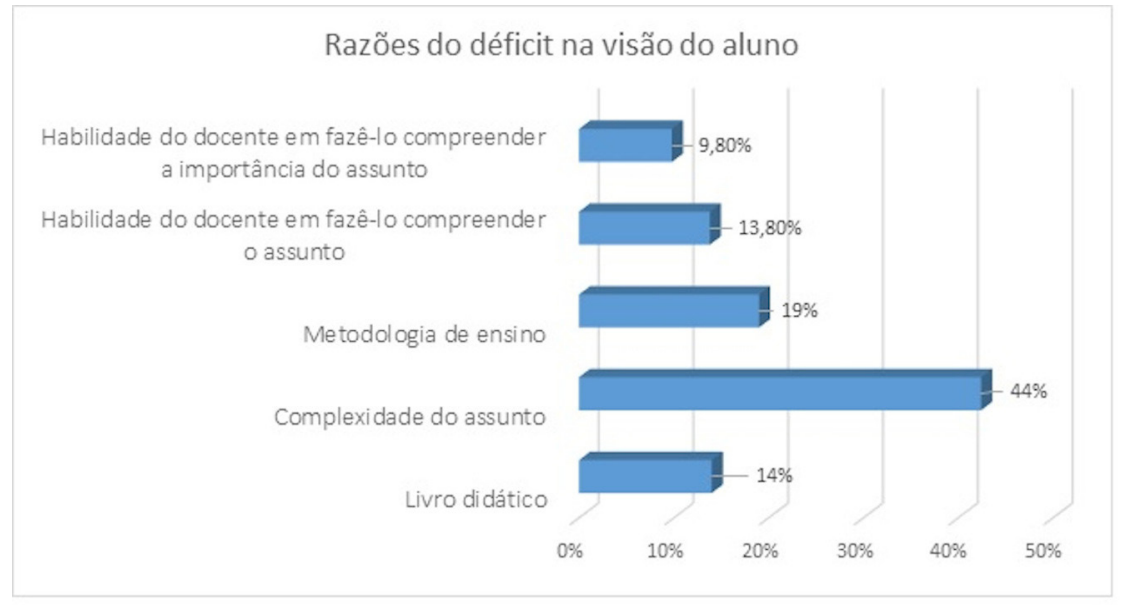

Fonte: elaborada pelos autores.

Para a parte do instrumento que buscou mensurar a aceitação e a afinidade dos alunos do curso $\mathrm{D}$ com ferramentas de ensino, $86,2 \%$ informaram acreditar que aulas práticas de meiose em laboratórios ajudam a absorver o assunto; $72,4 \%$ que estratégias de ensino como simuladores digitais, que interagindo/simulando as fases da meiose, ajudá-los-iam a absorver melhor o assunto e 65,5\% que estratégias de ensino manuais, como montagem de instrumentos com fios e cordas, simulando as fases da meiose, ajudá-los-iam melhor que a forma digital.

Além disso, 62,1\% dos alunos disseram que uma revisão teórica do assunto orientada por um professor não seria melhor que as demais estratégias citadas. 


\section{Discussão}

Esta pesquisa não teve como objetivo a comparação entre cursos e Instituição de Ensino Superior, isto é, não buscou identificar o melhor ou pior curso, ou se a metodologia de ensino de uma Instituição de Ensino Superior pública é melhor ou pior que uma Instituição de Ensino Superior privada. A busca se concentrou na identificação dos níveis de aprendizagem, contabilizando as respostas de forma direta e avaliando a qualidade delas. Os resultados foram reveladores, com destaque para o pós-aula de meiose na graduação.

Cada um dos quatro cursos analisados demonstrou uma particularidade. No curso A, observamos um aspecto bimodal em uma sala de aula, ocorrendo uma concentração de alunos afirmando não terem aprendido o assunto. No curso B, igualmente ao curso D, uma alta porcentagem de alunos se atribuiu nota zero na autoavaliação. $O$ curso $C$ demonstrou nível satisfatório em todas as questões, mas, ao se autoavaliarem, foram severos, dando-se notas baixas.

Alguns autores como Lewis e Wood (2000) e Saka et al. (2006) relatam a problemática que envolve a dificuldades de alunos de todos os níveis escolares em compreender os conceitos da Biologia, com ênfase na célula, confirmando os resultados apresentados por este trabalho. Os déficits do ensino de Ciências e Biologia no ensino básico são observados há muito tempo, mas a constatação de que, mesmo após os ensinamentos do assunto nos cursos de graduação, ainda continue com uma absorção insatisfatória pelos alunos, causa preocupação e leva à busca por estratégias que possam minimizar esse déficit. Na opinião da maioria dos alunos, o motivo de não aprenderem com totalidade o assunto foi a sua complexidade.

O fator impactante no resultado consolidado das questões específicas sobre meiose no segundo Instrumento Avaliativo foram o déficit com relação à recombinação e variabilidade genética, em que $90,30 \%$ dos alunos não alcançaram uma resposta satisfatória; esse resultado confirma a falta de uma construção sólida no conhecimento. Sobre esse assunto, quando questionados sobre os resultados finais do processo de meiose, 56,8\% demonstraram conhecimentos sobre a questão e $59 \%$ de acertos, quando questionados sobre as fases da meiose e seus eventos, apesar de mais da metade reproduzir o assunto, ainda ocorre um preocupante déficit de aprendizagem. No conjunto, os resultados demonstram também que os alunos apreendem e são capazes de se referir aos conceitos da meiose, mas o ato de refletir e associar os conceitos constituem uma defasagem dentro do processo ensinoaprendizagem (E-A).

Um aspecto relevante nesta análise está na diferença de metodologias de ensino usadas pelas Instituição de Ensino Superior. Percebe-se com esse resultado que, independentemente da metodologia, quando a complexidade do assunto não é tratada de forma real, o aprendizado não ocorre em níveis satisfatórios, principalmente conceitos mal trabalhados em níveis básicos, no caso, os alunos deixam o ensino médio sem um aprendizado concretizado.

Segundo Wood Jr. (2000), ocorre uma precariedade na estruturação que leva à formação de profissionais, com déficits em relação às exigências do mercado de trabalho. Para Colossi, Consentino e Queiroz (2001), outro fator que impacta na precariedade da formação profissional seria o distanciamento dos conteúdos estudados e a velocidade das mudanças no conhecimento científico e tecnológico, reforçando um apelo à flexibilidade nas formas de ensinar. 
Os modelos educacionais usados por grande parte das Instituição de Ensino Superior seguem um planejamento didático que define o conteúdo e a forma que a matéria deve ser desenvolvida. No entanto, a transferência de um pacote de ensino pronto pode acarretar passividade e deficiências reflexivas. Assim, a flexibilidade na forma de aplicação do conteúdo deve propiciar ajustes que visem ao melhor aproveitamento pelos alunos. Os métodos pedagógicos podem aperfeiçoar ou auxiliar na consolidação das competências que os discentes necessitam alcançar. Porém, mesmo com a adoção de estratégias pedagógicas no processo de ensino-aprendizagem, é correto destacar que o professor ainda é o detentor da melhor forma de aplicação e ajustes necessários, no momento correto, sempre visando à perspectiva positiva no ganho de aprendizado.

A finalidade do primeiro Instrumento Avaliativo foi definir se aluno concretizou a aprendizagem básica sobre meiose no Ensino Médio, assim possibilitando o mapeamento das ligações cognitivas para ampliar a complexidade do assunto no Ensino Superior. A pergunta sobre a Primeira Lei de Mendel revela que há pouca atribuição de funcionalidade ao conteúdo aprendido e, em particular, pouca capacidade ou esforço em associar o conteúdo da meiose com o de outras aulas, mais uma vez reforçando que o ensino-aprendizagem se dá de forma compartimentada, com pouco desenvolvimento de relações associativas e, principalmente, causais, entre assuntos de diferentes aulas e de diferentes disciplinas.

Nota-se que os cursos pré-vestibulares são colaboradores no apoio ao aprendizado. No entanto, tratando-se de assuntos complexos, ainda ocorre déficit tanto em alunos provenientes exclusivamente do Ensino Médio, como os de cursos preparatórios para vestibular. A análise referente à frequência em cursos pré-vestibulares confirmou que os alunos foram expostos aos conteúdos básicos de meiose e genética em mais de um momento e estão, portanto, melhor preparados para receber a complementação do ensinamento no nível superior. Esse aspecto foi relevante para o curso $C$, pois $63 \%$ dos alunos mencionaram atribuir o aprendizado da meiose aos cursos preparatórios para o vestibular. Nos demais cursos, não se observou uma porcentagem expressiva de alunos em cursos pré-vestibulares e, mesmo com essa diferença, no resultado final, todos os quatro cursos não obtiveram um resultado satisfatório ao serem expostos à aplicação do conteúdo específico. Com esse resultado, observou-se que, como citado por Borges e Lima (2007), a grande maioria dos discentes deixa o Ensino Médio com entendimento equivocado das Leis de Mendel. E as respostas confirmam que a maioria dos discentes tem seus conhecimentos de meiose adquiridos no Ensino Médio, com exceção do curso $C$, em que dois terços dos alunos frequentaram cursos preparatórios.

Com o segundo Instrumento Avaliativo foi possível desenvolver um mapeamento do déficit de aprendizagem dos conceitos ensinados de meiose no nível superior, levando a um direcionamento em relação à recombinação e à variabilidade genética, bem como ao evento de crossing over.

O instrumento procurou ainda compreender, na visão do aluno, os motivos que os levaram a um aprendizado insatisfatório. Outro aspecto analisado por este estudo está relacionado à aceitação por parte dos alunos em usar estratégias de ensino como ferramentas de ensino manuais e digitais. A aceitação dos alunos por ferramentas manuais foi de $68 \%$, refletindo uma tendência de metodologias de ensino ativas, cujo modelo ouvir e reproduzir perde forças, e situações que incentivam a prática e as discussões crescem. Essa ideia é reforçada por Roman et al. (2017) ao citar as transformações das metodologias de ensino para a área de Saúde, e ainda destacar a pirâmide de Glasser como exemplo. William Glasser foi um psiquiatra norte-americano que acreditou em um ensino mais ativo, e demostrou sua teoria em 
uma pirâmide, na qual o modelo de ensino expositivo, com meios tradicionais como ler, ver e escutar ficam representados no topo da pirâmide e práticas reais contendo diálogo, discussão com meios que ensinam a expor ideias, resolver problemas, são mais efetivos na absorção do conhecimento e no processo de aprendizagem. Essas ações requerem uma participação mais ativa do aluno e maior dedicação aos conteúdos a serem aprendidos, representados, portanto, na base da pirâmide. Uma representação dessa pirâmide poderia ser exemplificada da seguinte forma: ao ensinar, teríamos um aprendizado de 95\%; ao manipular ou fazer algo, aprendemos até $80 \%$, aqui podemos incluir práticas e ferramentas de ensino usando tecnologia pedagógica; aprendemos $70 \%$ quando discutimos com alguém, com destaque para as ferramentas de ensino que estimulam discussões em sala; aprendemos $50 \%$ quando vemos e ouvimos; $30 \%$ quando observamos; $20 \%$ quando ouvimos e somente $10 \%$ quando lemos.

Após todas as análises da quantidade e qualidade das respostas dos dois instrumentos, conclui-se que os alunos aprendem a reproduzir o que está no livro, mas têm níveis insatisfatórios para correlacionar assuntos interligados, não relacionando a aspectos do cotidiano ou outros assuntos e/ou disciplinas. Dessa forma, a aprendizagem não sofre um crescente, torna-se fragmentada de forma impactante para os processos cognitivos.

Concluímos que a fixação de conteúdos deve ser reforçada pela busca de articulação com outras disciplinas, reforço dos aspectos quantitativos e pelo desenvolvimento de ferramentas pedagógicas que facilitem a compreensão dos processos envolvidos na meiose.

\section{Referências}

ALBERTS, B. et al. Biologia molecular da célula. 6. ed. Porto Alegre: Artmed, 2017.

BORGES, C. K. G. D.; SILVA, C. C.; REIS, A. R. H. As dificuldades sobre a aprendizagem das Leis de Mendel enfrentadas por alunos do ensino médio. Experiência em Ensino de Ciências, Cuiabá, v. 12, n. 6. p. 61-75. 2017. Disponível em: https://tinyurl.com/ycu36gfe. Acesso em: 21 set. 2018.

BORGES, R. M. R.; LIMA, V. M. R. Tendências contemporâneas do ensino de biologia no Brasil. Revista Eletrónica de Enseñanza de las Ciências, Vigo, v. 6, n. 1, p. 165-175, 2007. Disponível em: https:// tinyurl.com/y7woxpeq. Acesso em: 3 jan. 2019.

CARABETTA, V. J. Rever, pensar e (re)significar: a importância da reflexão sobre a prática na profissão docente. Revista Brasileira de Educação Médica, Rio de Janeiro, v. 34, n .4, p. 580-586, 2010. DOI: http://doi.org/d4xnvt.

CARVAlHO, H. F.; RECCO-PIMENTEL, S. M. A célula. 3. ed. São Paulo: Manole, 2013. p. 544.

COLOSSI, N.; CONSENTINO, A.; QUEIROZ, E. G. Mudanças no contexto do ensino superior no Brasil: uma tendência ao ensino colaborativo. Revista da FAE, Curitiba, v. 4, n. 1, p. 55-58, 2001.

GOLDBACH, T.; EL-HANI, C.; MARTINS, R. C. Idéias sobre gene em revistas de divulgação científica e em glossários virtuais. In: ENCONTRO NACIONAL DE PESQUISA EM EDUCAÇÃO EM CIÊNCIAS, 5. Bauru, 2009. Atas [...]. Disponível em: https://tinyurl.com/yc8qnehs. Acesso em: 1 out. 2018.

KLAUTAU-GUIMARÃES, M. N.; MOREIRA, A.; ROCHA, D. M. S.; OLIVEIRA, S. F.; JESUS, H.; CORREIA, A. Relação entre herança genética, reprodução e meiose: um estudo das concepções de estudantes universitários do Brasil e Portugal. Enseñanza de las Ciencias, Barcelona, p. 2260-2263, 2009.

(Número extra). Disponível em: https://tinyurl.com/y9wmerrt. Acesso em: 11 set. 2018. 
KRASILCHIK, M. Reforma e realidade: o caso do ensino de ciências. São Paulo em Perspectiva, São Paulo, v. 14, n. 1, p. 85-93, 2000. DOI: http://doi.org/fqwr6d.

LEWIS, J.; WOOD, R. C. Genes, chromosomes, cell division and inheritance: do students see any relationships? International Journal of Science Education, London, v. 22, n. 2, p. 177-195, 2000.

LIMA, A. C.; PINTON, M. R. G. M.; CHAVES, A. C. L. O entendimento e a imagem de três conceitos: DNA, gene e cromossomo no ensino médio. In: ENCONTRO NACIONAL DE PESQUISA EM EDUCAÇÃO EM CIÊNCIAS, 6., 2007, Florianópolis. Anais [...]. Disponível em: https://tinyurl.com/y7tkxgvp. Acesso em: 25 set. 2018.

LORBIESKI, R.; RODRIGUES, L. S. S.; D'ARCE, L. P. G. Trilha meiótica: o jogo da meiose e das segregações cromossômica e alélica. Genética na Escola, Ribeirão Preto, v. 5, n. 1, p. 25-33, 2010. Disponível em: https://tinyurl.com/y8o4vm9u. Acesso em: 10 ago. 2018.

MOURA, J.; DEUS, M. S. M.; GONÇALVES, N. M. N.; PERON, A. P. Biologia/genética: o ensino de biologia, com enfoque a genética, das escolas públicas no Brasil: breve relato e reflexão. Semina: ciências biológicas e da saúde, Londrina, v. 34, n. 2, p. 167-174, 2013. DOI: http://doi.org/dzm5.

ROMAN, C.; ELLWANGER, J.; BECKER, G. C.; SILVEIRA, A. D.; MACHADO, C, L. B.; MANFROI, W. C. Metodologias ativas de ensino-aprendizagem no processo de ensino em saúde no Brasil: uma revisão narrativa. Clinical Biomedical Research, Porto Alegre, v. 37, n. 4, p. 349-357, 2017.

SAKA, A.; CERRAH, L.; AKDENIZ, A. R.; AYAS, A. A cross-age study of the understanding of three genetic concepts: how do they image the gene, DNA and chromosomes? Journal of Science Education and Technology, Dordrecht, v. 15, n. 2, p. 192-202, 2006. Disponível em: https://tinyurl. com/ydxu6cr8. Acesso em: 30 jul. 2019.

SALIM, D. C.; AKIMOTO, A. K.; PEDROSA, M. A. F.; KLAUTAU-GUIMARÃES, M. N.; OLIVEIRA, S. F. O baralho como ferramenta no ensino de genética. Genética na Escola, Ribeirão Preto, v. 2, n. 1, p. 6-9, 2007. Disponível em: https://tinyurl.com/y9jks2e4. Acesso em: 3 jan. 2019.

SILVA, M. O.; CICILLINI, G. A. O potencial das discussões polêmicas nas aulas de biologia. In: SEMANA DO SERVIDOR, 4., e SEMANA ACADÊMICA, 5. 2008, Uberlândia. Atas [...]. Disponível em: https:// tinyurl.com/y7pzgk46. Acesso em 03 jan. 2019.

WOOD JR, T. Reformando o ensino e o aprendizado de gestão da produção e operações. In: SIMPÓSIO DE ADMINISTRAÇÃO DA PRODUÇÃO, LOGÍSTICA E OPERAÇÕES INTERNACIONAIS, 2., 2000. São Paulo. Anais [...] São Paulo: EAG: FGV, 2000. 